\title{
Excuses to continue smoking: The role of disengagement beliefs in smoking cessation
}

\author{
Marloes Kleinjan ${ }^{\mathrm{a}, \mathrm{c}, *}$, Regina J.J.M. van den Eijnden ${ }^{\mathrm{a}}$, Arie Dijkstra ${ }^{\mathrm{b}}$, \\ Johannes Brug $^{c}$, Rutger C.M.E. Engels ${ }^{\mathrm{d}}$ \\ a Addiction Research Institute (IVO), Heemraadssingel 194, 3021 BD Rotterdam, The Netherlands \\ ${ }^{\mathrm{b}}$ Social and Organizational Psychology, University of Groningen, Grote Kruisstraat 2/1, 9712 TS Groningen, The Netherlands \\ ${ }^{\mathrm{c}}$ Department of Public Health, Erasmus University Medical Centre, PO Box 2040, 3000 CA Rotterdam, The Netherlands \\ ${ }^{\mathrm{d}}$ Behavioural Science Institute, Radboud University Nijmegen, PO Box 9104, 6500 HE Nijmegen, The Netherlands
}

\begin{abstract}
Background: The aim of the present study was to investigate the role of disengagement beliefs in smoking cessation. The association of disengagement beliefs with forward transition through the transtheoretical stages of change and self-reported quitting were examined, with and without adjusting for processes of change.

Methods: A longitudinal survey was conducted among Dutch smokers, resulting in 367 respondents who completed two questionnaires, one at baseline and one at 8 months follow-up. Disengagement beliefs, intention to quit, actual quitting, and the processes of change were assessed.

Results: The findings showed that disengagement beliefs were negatively associated with forward stage transition and actual quitting. Processes of change only partly mediated these associations.

Conclusions: Adhering to disengagement beliefs seems to be an inhibitor of progression towards smoking cessation and actual quitting, also after adjustment for processes of change.
\end{abstract}

(C) 2006 Elsevier Ltd. All rights reserved.

Keywords: Disengagement beliefs; Stages of change; Processes of change; Smoking cessation

* Corresponding author. Addiction Research Institute (IVO), The Netherlands. Tel.: +31 10 4253366; fax: +31 102763988. E-mail addresses: Kleinjan@ivo.nl (M. Kleinjan), Eijnden@ivo.nl (R.J.J.M. van den Eijnden), A.Dijkstra@ppsw.rug.nl (A. Dijkstra), J.Brug@erasmusmc.nl (J. Brug), R.Engels@bsi.ru.nl (R.C.M.E. Engels). 


\section{Introduction}

Health education programs, mass media campaigns, and nowadays even the slogans depicted on cigarette packages, warn smokers for the harmful health effects of smoking. Despite all these efforts, many people continue to smoke. Because of the well-known negative health consequences of smoking, and the high resistance of smokers to change, it can be assumed that some form of cognitive dissonance reduction occurs in smokers, especially those not willing to quit (Chapman, Wong, \& Smith, 1993). Cognitive dissonance is experienced when an individual has two or more cognitions that are dissonant in relation to one another, which results in motivational tension (Festinger, 1957; Wicklund \& Brehm, 1976). Smokers can be expected to experience cognitive dissonance, because they continue to smoke cigarettes despite their knowledge of the hazardous effects (McMaster \& Lee, 1991).

Dissonance reduction in the form of denial or distortion of threatening information may affect potential readiness to change in a negative manner. Bandura labeled this denial or distortion of threatening information as disengagement (Bandura, 1986; Bandura, Barbaranelli, Caprara, \& Pastorelli, 1996). In smokers, disengagement can emerge in the form of certain beliefs that are used as excuses or justifications for continuing smoking. For example, smokers may downplay the effect of smoking on health, or they may point out the dangers of other lifestyles. Smokers do indeed hold more of these cognitive dissonance-reducing beliefs than ex-smokers do, which may indicate that successful cessation is accompanied by the shedding of dissonance-reducing beliefs (Chapman et al., 1993).

Several studies have found that holding disengagement beliefs is related to intentions to quit smoking and to undertaking quit attempts. Smokers who had the intention to quit adhered to significantly fewer beliefs (Johnson, 1968; Olshavsky \& Summers, 1974), and disengagement beliefs at baseline were found to be associated with the likelihood of undertaking a quit attempt in the future (Dijkstra, 2003; Dijkstra \& Brosschot, 2003; Dijkstra, De Vries, Kok, \& Roijackers, 1999). Disengagement beliefs may prevent smokers from seriously thinking about, or considering the consequences of their behavior, and could therefore lead to stagnation in the progression towards quitting. In a cross-sectional study by Oakes, Chapman, Borland, Balmford, and Trotter (2004) on self-exempting beliefs (a construct similar to disengagement beliefs, i.e., beliefs about personal immunity to health effects, skepticism about medical evidence, normalizing dangers of smoking because of the abundance of risks, and beliefs that smoking is worth probable health damage), the ability of these beliefs to predict intention to quit was explored, using a modified version of the stage of change model. Self-exempting beliefs were found to be related to interest in quitting, but some types of beliefs had greater influence than others on the progression towards cessation. Beliefs that smoking is worth probable health damage were most closely negatively related to intention to quit and thereby the only significant discriminator between the smoker categories of precontemplators, contemplators and preparers.

The present study further explored the role of disengagement beliefs in the continuation of smoking behavior. In this longitudinal study, we more closely examined the association between disengagement beliefs and smoking cessation. Results of previous studies already showed that disengagement beliefs are associated with both intention to quit (Dijkstra, 2003; Dijkstra \& Brosschot, 2003; Dijkstra et al., 1999; Oakes et al., 2004; Olshavsky \& Summers, 1974) and quit attempts (Dijkstra, 2003; Dijkstra and Brosschot, 2003; Dijkstra et al., 1999). The remaining question, however, is how adhering to disengagement beliefs lowers the intention to quit and results in less quitting? To explore this issue, using a longitudinal design, we first assessed if disengagement beliefs are associated with forward transitions through the different stages of behavioral change and with actual cessation. Furthermore, 
we explored if these associations remained after statistical adjustment for processes of change, and to what extent such processes may mediate the associations of disengagement beliefs with forward transition through the stages of behavior change and actual cessation.

Over the years, several models to assess behavioral change have been postulated. In the area of substance abuse, the stage of change model has become increasingly influential for assessing motivations to alter behavior (Connors, Donovan, \& DiClemente, 2001; Stephens, Cellucci, \& Gregory, 2004). This stage model defines five stages toward successful behavioral change. The stages are defined in terms of an individual's past behavior and his or her plans for future action, and represent a temporal dimension in which shifts occur in motivation to quit smoking (Prochaska, DiClemente, \& Norcross, 1992). The first stage is precontemplation, in which the smoker is unaware or under-aware of the risks of smoking, and shows no intention to quit in the near future. The next stage is the contemplation stage, in which the smoker is thinking about the risks of smoking and considers change. Intending to take action and small behavioral changes are indicative of the next stage, i.e., the preparation stage, and in the action stage the smoker has recently quit smoking. The final stage is the maintenance stage, in which the smoker works to prevent relapse and which is reached when non-smoking was sustained for more than 6 months (Prochaska et al., 1992).

Certain processes are known to act as predictors of progress across the stages of change (Prochaska et al., 1992; Prochaska, Norcross, Fowler, Follick, \& Abrams, 1992). These processes of change are overt as well as covert activities and experiences that individuals engage in, in order to attempt to change risk behaviors. In addition, they can facilitate understanding of how shifts occur in motivation to change. Each of the separate processes includes distinct methods and interventions that contribute differentially to the completion of the different stages of behavior change (Prochaska et al., 1992). The processes of change can be grouped into two higher-order factors, i.e., cognitive-affective processes and behavioral processes (Kristeller, Rossi, Ockene, Goldberg, \& Prochaska, 1992; O'Connor, Carbonari \& DiClemente, 1996; Prochaska, Velicer, DiClemente, \& Fava, 1988). The processes of environmental evaluation, self-evaluation, consciousness raising, and dramatic relief, tend to be used most frequently during the contemplation and preparation stages of change and can be classified as cognitive-affective processes, whereas the processes of reinforcement management, counterconditioning, stimulus control, and helping relationship occur most frequently during the action and maintenance stages of change and can be classified as behavioral processes (Prochaska et al., 1992; Rosen, 2000; see Table 1).

Engaging in processes of change is expected to instigate change in smoking, whereas engaging in disengagement beliefs will lead to continuation of smoking. It is further expected that disengagement beliefs precede the processes of change, and that processes of change precede movement across the stages of change and actual smoking cessation. Smokers are considered to perceive a fairly constant threat by knowing they are susceptible to possible health damage due to smoking. This threat will become less worrisome when disengagement beliefs are used to deny or distort this knowledge or the information that gives rise to this knowledge. Because of the lowered threat, the need for engaging in a threat-related process of change becomes more obsolete. For example, the process of consciousness raising may be promoted by perceived threat, because threatening knowledge or information increases the need for reassessing one's smoking behavior. Adhering to strong disengagement beliefs lowers the perceived threat, and may thereby decrease the need for reassessment of one's smoking. Adhering to more disengagement beliefs is assumed to prevent engagement in the different processes of change. Another example of a cognitive-affective process is dramatic relief; the process of dramatic relief is in itself a parameter of threat. When the threat is removed by disengagement beliefs, a confrontation with the 
Table 1

Sample items for the processes of change

\begin{tabular}{|c|c|c|}
\hline Processes & Description & Sample item \\
\hline $\begin{array}{l}\text { Environmental } \\
\text { evaluation }\end{array}$ & $\begin{array}{l}\text { Considering how smoking affects one's } \\
\text { environment }\end{array}$ & I notice that more people disapprove of smoking \\
\hline Self-evaluation & $\begin{array}{l}\text { Considering feelings and thoughts about the } \\
\text { self in relation to one's smoking }\end{array}$ & $\begin{array}{l}\text { I feel disappointed in myself because of my need } \\
\text { to smoke }\end{array}$ \\
\hline $\begin{array}{l}\text { Consciousness } \\
\text { raising }\end{array}$ & $\begin{array}{l}\text { Increasing knowledge and information about } \\
\text { one's smoking }\end{array}$ & I remember information about quitting smoking \\
\hline Dramatic relief & $\begin{array}{l}\text { Experiencing and expressing feelings about } \\
\text { one's smoking }\end{array}$ & $\begin{array}{l}\text { Information about the consequences of smoking } \\
\text { frightens me }\end{array}$ \\
\hline $\begin{array}{l}\text { Reinforcement } \\
\text { management }\end{array}$ & $\begin{array}{l}\text { Rewarding oneself or being rewarded by } \\
\text { others for changing smoking behavior }\end{array}$ & I reward myself if I don't smoke \\
\hline Counterconditioning & Replacing smoking with alternatives & I replace smoking by something else \\
\hline Stimulus control & $\begin{array}{l}\text { Avoidance or dealing with stimuli that bring } \\
\text { out smoking }\end{array}$ & I avoid places where people smoke \\
\hline Helping relationship & $\begin{array}{l}\text { Trust others and being open about one's } \\
\text { smoking }\end{array}$ & $\begin{array}{l}\text { I ask people who are near to me to help me not } \\
\text { to smoke }\end{array}$ \\
\hline
\end{tabular}

adverse effects of smoking will lead to less dramatic relief. The behavioral processes of reinforcement management, counterconditioning, stimulus control, and helping relationship are different from the cognitive-affective processes, for they are most frequently used during the action and maintenance stages of change and therefore mostly regarded as aids not to smoke. The use of these processes in smokers is directed by acute threat. Acute threat causes fear and therefore a motivation to stop or reduce smoking. Strong disengagement beliefs decrease the threat and by this the necessity of the use of processes that help to stop or to reduce smoking.

The first goal of the present longitudinal study is to examine if disengagement beliefs are related to less forward stage transition through the stages of change and, in addition, to assess whether disengagement beliefs are related to actual quitting. Engaging in disengagement beliefs is expected to be associated with less forward stage transition and less actual quitting (Hypothesis 1).

The second goal is to assess whether there is a negative relation between the degree of disengagement beliefs one has about smoking and the activities and experiences one is engaged in when attempting to quit smoking, i.e., the processes of change (Hypothesis 2).

The final goal of the present study is to assess if the processes of change are positively related to forward stage transition and actual quitting, and, if that is the case, to assess if the processes of change mediate the relation between disengagement beliefs and forward stage transition, and the relation between disengagement beliefs and actual quitting (Hypothesis 3).

\section{Method}

\subsection{Recruitment}

Smokers were recruited by means of advertisements in local newspapers throughout The Netherlands. Smokers who were not planning to quit, smokers who were planning to quit, and ex- 
smokers were asked to participate on a voluntary basis in a research project on smoking and smoking cessation. The group of ex-smokers was not included in this study. A chance to win one of ten bonus prices of $\$ 100$ was offered to participants who would complete the two questionnaires. After participants had registered at the University by means of a phone call $(N=800)$, the T1 questionnaire (including a pre-paid envelope to return the questionnaire) was sent to them. At T1, 423 smokers responded. A total of 19 participants were excluded because they were cigar or pipe smokers, as well as one person who was under aged (15 years old). Furthermore, after casewise listing of residuals in logistic regression analyses on model variables, seven outliers were omitted from the analyses, leaving a total of 396 respondents at T1. Subsequently, 8 months later the second questionnaire (T2) was sent, and was returned by 367 participants (93\% of the $396 \mathrm{~T} 1$ respondents).

\subsection{Measures}

The demographic variables measured were gender, age, and education level. Educational level was categorized as low, medium, or high. Schooling systems in The Netherlands refer to vocational training as low, advanced vocational training as medium, and college/university training as high.

Smoking and quitting behavior was assessed in terms of the number of years smoked, the number of cigarettes smoked per day, the number of quit attempts, and the duration of the longest quit attempt. Actual quitting was measured by the question: "Have you quit smoking or are you currently engaged in a quit attempt?" (Yes/No).

Biochemical verification of the self-report quitting behavior was not conducted for several reasons. First, an increase in non-response and dropout was expected had biochemical verification been required. Secondly, the present study was considered to be one of low demand. Hence, several studies indicated that self-reported smoking behavior can be considered valid (Velicer, Prochaska, Rossi, \& Snow, 1992).

\subsubsection{Disengagement beliefs}

Disengagement beliefs were assessed using a scale consisting of twelve items. This scale has been tested and validated in earlier studies (Dijkstra \& Brosschot, 2003; Dijkstra et al., 1999). The items consisted of reasons or excuses why it would be okay to smoke, regardless of the well-known harmful health effects. Examples of items are: "I know heavy smokers who live long" and "I have to die of something". The items could be scored on a 5-point scale ranging from I do not agree (1) to I do agree (5) and were constructed such that the respondent had to finish the sentence: "Smoking can make me ill, but...". Cronbach's $\alpha$ was 0.84 . Table 2 shows the results of the factor analysis (PCA) and the mean and standard deviation (S.D.) of the 12 items of the disengagement beliefs scale.

\subsubsection{Stages of change}

The stages of change were measured by asking respondents to indicate if and when they planned to stop smoking on a 9-point ordinal scale ranging from 1 ("I I am planning to quit within the next 10 days") to several levels ("planning to quit within one month", "planning to quit within six months", "planning to quit within one year", "planning to quit within five years", "planning to quit within ten years", "planning to quit somewhere in the future but not within the next 10 years", "planning to never quit but planning to cut down") to 9 ("planning to never quit and not planning to cut down"). 
Table 2

Pattern matrix, means and standard deviations for disengagement beliefs

\begin{tabular}{|c|c|c|c|}
\hline Smoking can make me ill, but... & Factor loading & Mean & S.D. \\
\hline Pollution is just as unhealthy & 0.72 & 3.47 & 1.43 \\
\hline There are lots of risks in life & 0.68 & 3.70 & 1.30 \\
\hline Everything is unhealthy & 0.67 & 3.08 & 1.40 \\
\hline You have to die of something & 0.66 & 2.47 & 1.44 \\
\hline Everyone acts unhealthy sometimes & 0.64 & 3.76 & 1.22 \\
\hline Not everyone gets sick smoking & 0.63 & 4.13 & 1.04 \\
\hline Know heavy smokers that lived long & 0.62 & 3.77 & 1.26 \\
\hline Medical science will invent something & 0.60 & 2.46 & 1.22 \\
\hline Rather a short/good life than a long/boring life & 0.55 & 3.13 & 1.45 \\
\hline If it were really bad, it would be forbidden & 0.52 & 2.38 & 1.43 \\
\hline I live healthy otherwise & 0.47 & 3.58 & 1.18 \\
\hline Health is not the only thing in life & 0.42 & 2.50 & 1.44 \\
\hline$\%$ Variance & 36.40 & & \\
\hline
\end{tabular}

Factor analysis by principal component analysis.

Preparers were those respondents who agreed on planning to quit within the next ten days or the next month, whereas those who agreed on planning to quit within the next 6 months were designated as contemplators. Precontemplators were those respondents who were planning to quit within the next year or the next 5 years, but not in the next 6 months, those who agreed to quit somewhere in the future but not within 5 years, or those who had no plans to quit at all (Dijkstra, Bakker, \& De Vries, 1997; Dijkstra, Roijackers, \& De Vries, 1998; Dijkstra, Tromp, \& Conijn, 2003).

\subsubsection{Processes of change}

The processes of change were assessed by four cognitive-affective and four behavioral processes of the processes of change [17]. The cognitive-affective processes used are: Environmental evaluation (6 items), Self-evaluation (3 items), Consciousness raising (6 items), and Dramatic relief (3 items). The behavioral processes of change are: Reinforcement management (5 items), Counterconditioning (5 items), Stimulus control (7 items), and Helping relationship (5 items). The items could be scored on a 5point scale ranging from (0) never to (4) often, and followed the question: "How often did the following occur in the last four weeks?". Examples of the items used to measure the processes of change are shown in Table 1. The reliabilities of the scales were found to be good to excellent (Cronbach's $\alpha$ ranges from 0.74 to 0.93$)$.

\subsection{Attrition analysis}

Of the 396 respondents at T1, 7\% did not fill out the questionnaire at T2, leaving 367 participants in the prospective study cohort. Dropouts were compared with remaining respondents on the variables gender, age, education, disengagement beliefs, stages of change, processes of change, and number of cigarettes a day using logistic regression. Dropout was significantly predicted by stage of change (odds ratio $(\mathrm{OR})=1.75, p<0.05,95 \%$ confidence interval $(\mathrm{CI})=1.09-2.82)$. Further analyses using Chi-square values showed that participants in the preparation and precontemplation stage dropped out more frequently, than participants in the contemplation stage. In addition, higher scores on self-evaluation, consciousness raising, and stimulus control significantly predicted dropout $(\mathrm{OR}=1.43,95 \% \mathrm{CI}=1.07-$ 
1.91, $p<0.05$ for self-evaluation; $\mathrm{OR}=1.49,95 \% \mathrm{CI}=1.08-2.07, p<0.05$ for consciousness raising; and OR $1.95,95 \% \mathrm{CI}=1.10-3.47, p<0.05$ for stimulus control). Respondents who scored higher on evaluating feelings and thoughts about their own smoking, who more actively increase their knowledge and information about smoking, and who reported more avoidance of or dealing with stimuli that bring out smoking, were more likely to drop out.

\subsection{Sample characteristics}

Of the 367 respondents included in T1 and T2, 71.1\% was female; $21.8 \%$ had a low education, $45.7 \%$ had a medium education, and $31.9 \%$ of the respondents had a high education. The mean age was 43.78 years (S.D. $=13.5$, range 16-80). On average respondents smoked 19 cigarettes a day (S.D. $=9.7$, range 1-60). At T2, 103 respondents reported at least one attempt to quit smoking and 34 respondents reported to have actually quit smoking. At T1, there were 290 respondents classified as precontemplators, 43 as contemplators, and 34 as preparers. At T2, 280 respondents were classified as precontemplators, 32 as contemplators, and 20 as preparers. A total of 34 respondents had moved into the action stage at T2 and 1 respondent moved to the maintenance stage. 71 respondents reported forward stage transition and 43 respondents reported backward stage transition.

\subsection{Statistical analyses}

To explore if disengagement beliefs differed between stages of change, ANOVAs were conducted. To examine whether disengagement beliefs are associated with forward stage transition, logistic regression analyses were conducted to estimate ORs with $95 \%$ CIs for forward stage transition. Stage transitions are considered forward if a respondent moves from one stage at T1 to a latter stage at T2. Analyses were carried out for precontemplators, contemplators, and preparers taken together as one group, and, in addition, separate analyses were done for the group of precontemplators only. The reason to analyze the group of precontemplators as a separate group is partly based on previous research, which found that smokers who hold self-exempting beliefs are more likely to be in the precontemplation stage of change (Oakes et al., 2004). Disengagement beliefs can be considered a fundamental process that may prevent the smoker from seriously thinking about or considering the consequences of his or her behavior; therefore, the group of precontemplators is particularly likely to engage in disengagement beliefs. The distinction between precontemplators, contemplators, and preparers as one group and the precontemplators as a separate group, was also made when conducting the logistic regression analyses to assess whether disengagement beliefs significantly predict actual quitting at T2.

For the examination of the relation between disengagement beliefs and the processes of change, Pearson correlations were computed. To assess whether processes of change mediate the relationship between disengagement beliefs and respectively forward stage transition and actual quitting, mediation analyses were conducted according to the method described by Baron and Kenny (1986). First, forward stage transition (dependent variable) was regressed on disengagement beliefs (independent variable). Second, the mediator was regressed on disengagement beliefs (the mediator being one of the processes of change). Finally, forward stage transition was regressed on both disengagement beliefs and the mediator variables. Mediation was considered to exist if the conditions proposed by Baron and Kenny (1986) were met. Disengagement beliefs should therefore be associated with both forward stage transition and the mediator, the mediator should be associated with forward stage transition, and disengagement beliefs may 
no longer be associated with forward stage transition after the mediator has been controlled for. Partial mediation was indicated when the association between disengagement beliefs and forward stage transition decreased, but had not fully disappeared after adding the mediator. To test whether the explained variance significantly increased after adding the mediator, and to establish whether the decrease of the effect of disengagement beliefs was large enough to indicate (partial) mediation, model chi-square values of the model including disengagement beliefs were deducted from the model chi-square values of the model including both disengagement beliefs and the mediator. If the remaining value was higher than 3.84 $(p=0.05)$, the increase of explained variance was considered significant (Voeten \& Van den Bercken, 2003). Mediation analyses were carried out for precontemplators, contemplators, and preparers at $\mathrm{T} 1$ taken together, and separately for the group of precontemplators at $\mathrm{T} 1$. The same procedure was employed to assess mediation of the processes of change in the relationship between disengagement beliefs and actual quitting. In the prospective analyses, gender, age, and education were entered as covariates. The relation between the number of cigarettes per day and forward stage transition and actual quitting respectively, appeared to be non-significant; therefore, the number of cigarettes smoked per day was not entered as a covariate in the prospective analyses.

\section{Results}

\subsection{Stages of change and smoking-related cognitions and characteristics}

Smokers in the three stages of behavioral change differ in the extent to which they adhere to disengagement beliefs (see Table 3). Scheffe's post-hoc analyses showed that precontemplators adhere significantly stronger to disengagement beliefs than contemplators.

Table 3

Stages of change and smoking-related cognitions and characteristics: cross-sectional analyses

\begin{tabular}{lcccc}
\hline & \multicolumn{2}{c}{ Means in stages of change (S.D.) } & & \\
\cline { 2 - 5 } & Precontemplators & Contemplators & Preparers & $F$ \\
\hline Disengagement beliefs & $3.31^{\mathrm{a}}(0.77)$ & $2.66^{\mathrm{b}}(0.78)$ & $3.10(0.72)$ & $14.56^{* * *}$ \\
Environmental evaluation & $1.84^{\mathrm{a}}(0.86)$ & $2.05(0.92)$ & $2.38^{\mathrm{b}}(0.86)$ & $6.55^{*}$ \\
Self-evaluation & $1.17^{\mathrm{a}}(1.09)$ & $2.54^{\mathrm{b}}(1.20)$ & $2.56^{\mathrm{b}}(1.05)$ & $47.49^{* * *}$ \\
Consciousness raising & $1.39^{\mathrm{a}}(0.95)$ & $2.91^{\mathrm{b}}(0.86)$ & $3.00^{\mathrm{b}}(0.89)$ & $84.91^{* * *}$ \\
Dramatic relief & $1.11^{\mathrm{a}}(0.86)$ & $1.45(0.74)$ & $1.90^{\mathrm{b}}(1.01)$ & $13.13^{* * *}$ \\
Reinforcement management & $0.40^{\mathrm{a}}(0.46)$ & $0.74^{\mathrm{b}}(0.73)$ & $0.80^{\mathrm{b}}(0.86)$ & $14.00^{* * *}$ \\
Counterconditioning & $0.72^{\mathrm{a}}(0.64)$ & $0.96(0.81)$ & $1.13^{\mathrm{b}}(0.99)$ & $6.38^{*}$ \\
Stimulus control & $0.25^{\mathrm{a}}(0.42)$ & $0.55^{\mathrm{b}}(0.61)$ & $0.75^{\mathrm{b}}(0.68)$ & $22.08^{* * *}$ \\
Helping relationship & $0.40^{\mathrm{a}}(0.49)$ & $1.05^{\mathrm{b}}(0.77)$ & $0.78^{\mathrm{b}}(0.65)$ & $30.94^{* * *}$ \\
Cigarettes per day & $19.66^{\mathrm{a}}(9.80)$ & $18.23(8.83)$ & $15.48^{\mathrm{b}}(9.15)$ & $2.94 *$ \\
Years smoked & $26.0(12.8)$ & $25.4(12.1)$ & $24.3(14.5)$ & 0.25 \\
Quit attempts & $2.06^{\mathrm{a}}(2.25)$ & $4.05^{\mathrm{b}}(4.04)$ & $4.00^{\mathrm{b}}(3.42)$ & $\left.16.32^{* * *}\right)$ \\
Longest quit attempt in days & $241.6(754.6)$ & $304.5(549.6)$ & $561.7(1253.05)$ & 2.30 \\
\hline
\end{tabular}

Means in the same row that do not share superscript differ at $p<0.05$ using Scheffe's post-hoc tests.

$* p<0.05$.

$* * * \quad p<0.001$. 
Smokers in the three stages of behavioral change also differ in the extent to which they engage in the eight processes of change included in this study (Table 3). For self-evaluation, consciousness raising, reinforcement management, stimulus control, and helping relationship, post-hoc tests showed less engagement in precontemplators than in contemplators, and also less in precontemplators than in preparers. For environmental evaluation, dramatic relief, and counterconditioning differences were shown between precontemplators and preparers, i.e., precontemplators showed less engagement in the processes than did preparers. Furthermore, the difference between the stages of change with regard to the number of cigarettes smoked per day appeared to be significant; this indicates that precontemplators smoked more cigarettes in one day than preparers. With respect to quit attempts, precontemplators reported fewer attempts to quit than contemplators and preparers did. Smokers in the three stages of behavioral change did not differ in the number of years smoked and duration of the longest quit attempt.

\subsection{Prediction of forward stage transition and actual quitting}

For the total group of smokers, findings from a logistic regression analysis showed that smokers who strongly adhered to disengagement beliefs at T1 showed significantly less forward stage transition (see Table 5). Strong disengagement beliefs at $\mathrm{T} 1$ were also associated with a lower probability of actual quitting at $\mathrm{T} 2$.

\subsection{Correlations between disengagement beliefs and processes of change}

In the total sample, disengagement beliefs were significantly correlated to six of the eight processes of change. Only environmental evaluation and counterconditioning did not significantly correlate with disengagement beliefs (see Table 4). The more smokers adhered to disengagement beliefs, the less likely they were to engage in self-evaluation, consciousness raising, dramatic relief, reinforcement management, and stimulus control, and the fewer helping relationships they perceived.

Table 4

Intercorrelations between processes of change and disengagement beliefs at $\mathrm{T} 1$

\begin{tabular}{|c|c|c|c|c|c|c|c|c|c|}
\hline & 1 & 2 & 3 & 4 & 5 & 6 & 7 & 8 & 9 \\
\hline 1. Disengagement beliefs & - & -0.02 & $-0.35 * * *$ & $-0.39 * * *$ & $-0.24 * * *$ & $-0.13 *$ & -0.08 & $-0.13 *$ & $-0.15^{* *}$ \\
\hline 2. Environmental evaluation & 0.06 & - & $0.48 * * *$ & $0.44 * * *$ & $0.57 * * *$ & $0.31 * * *$ & $0.17 * *$ & $0.19 * * *$ & $0.24 * * *$ \\
\hline 3. Self-evaluation & $-0.24 * * *$ & $0.45 * * *$ & - & $0.83 * * *$ & $0.63 * * *$ & $0.39 * * *$ & $0.25 * * *$ & $0.36^{* * *}$ & $0.38 * * *$ \\
\hline 4. Consciousness raising & $-0.32 * * *$ & $0.41 * * *$ & $0.78 * * *$ & - & $0.64 * * *$ & $0.44 * * *$ & $0.28 * * *$ & $0.38 * * *$ & $0.43 * * *$ \\
\hline 5. Dramatic relief & $-0.19 * *$ & $0.52 * * *$ & $0.65 * * *$ & $0.65 * * *$ & - & $0.41 * * *$ & $0.21 * * *$ & $0.29 * * *$ & $0.27 * * *$ \\
\hline 6. Reinforcement management & $-0.12^{*}$ & $0.25 * * *$ & $0.36^{* * *}$ & $0.42 * * *$ & $0.40 * * *$ & - & $0.54 * * *$ & $50 * * *$ & $0.59 * * *$ \\
\hline 7. Counterconditioning & -0.04 & 0.11 & $0.24 * * *$ & $0.24 * * *$ & $0.20 * * *$ & $0.50 * * *$ & - & $0.60 * * *$ & $0.32 * * *$ \\
\hline 8. Stimulus control & -0.10 & 0.10 & $0.32 * * *$ & $0.32 * * *$ & $0.29 * * *$ & $0.45 * * *$ & $0.54 * * *$ & - & $0.35 * * *$ \\
\hline 9. Helping relationship & -0.05 & $0.21 * * *$ & $0.28 * * *$ & $0.28 * * *$ & $0.21 * * *$ & $0.50 * * *$ & $0.26 * * *$ & $0.28 * * *$ & - \\
\hline
\end{tabular}

Correlations above diagonal represent the total sample; correlations below diagonal represent the group of precontemplators exclusively.

\footnotetext{
* $p<0.05$.

$* * p<0.01$.

*** $p<0.001$.
} 


\subsection{Processes of change as mediators}

\subsubsection{Forward stage transition}

For the total sample of smokers at T1, disengagement beliefs were significantly associated with forward stage transition (see Table 5; Nagelkerke $R^{2}=0.07$ ). The conditions for complete mediation were only met for consciousness raising (Table 5). Adding consciousness raising to the model significantly increased the explained variance (Nagelkerke $R^{2}=0.13 ; \chi^{2}(1, N=360)=11.98, p<0.01$ ) ${ }^{1}$ and the relation between disengagement beliefs and forward stage transition was no longer significant $(p=0.08)$. Selfevaluation, stimulus control, and helping relationship partially mediate the relation between disengagement beliefs and forward stage transition. Adding self-evaluation to the model resulted in a significant increase (Nagelkerke $R^{2}=0.08 ; \chi^{2}(1, N=361)=5.28, p<0.05$ ). Disengagement beliefs, however, remained significantly associated with forward stage transition (Table 5). Similar results were found for stimulus control and helping relationship, i.e., Nagelkerke $R^{2}=0.10\left(\chi^{2}(1, N=355)=5.93\right.$, $p<0.05)$ and Nagelkerke $R^{2}=0.12\left(\chi^{2}(1, N=356)=9.65, p<0.05\right)$, respectively. The processes of dramatic relief and reinforcement management were not found to be mediating factors in the association between disengagement beliefs and forward stage transition.

\subsubsection{Quitting}

The relation between disengagement beliefs and quitting was found to be significant (Table 5; Nagelkerke $R^{2}=0.04$ ). Mediation analyses showed three processes of change that completely mediated the relation between disengagement beliefs and quitting (see Table 5). Adding consciousness to the regression equation resulted in a non-significant association between disengagement beliefs $(p=0.36)$ and quitting, and a significant increase in the explained variance to Nagelkerke $R^{2}=0.07\left(\chi^{2}(1, N=362)=5.95, p<0.05\right)$. Similar results were found for stimulus control and helping relationship, i.e., Nagelkerke $R^{2}=0.07\left(\chi^{2}(1, N=357)=5.97, p<0.05\right)$ and Nagelkerke $R^{2}=0.06\left(\chi^{2}(1, N=358)=4.82, p<0.05\right)$, respectively, and the association between disengagement beliefs and quitting disappeared $(p=0.11$ and $p=0.11)$. In the relation between disengagement beliefs and quitting, no mediation effect was found for self-evaluation.

\subsection{Precontemplators only}

In precontemplators exclusively, adhering strongly to disengagement beliefs was related to less consciousness raising, self-evaluation, dramatic relief, and reinforcement management (see Table 4). Disengagement beliefs were also associated with forward stage transition (see Table 5; Nagelkerke $R^{2}=0.11$ ). Having stronger disengagement beliefs at $\mathrm{T} 1$ was related to a lower likelihood of forward stage transition. In precontemplators, stronger disengagement beliefs were not significantly associated with actual quitting $(\mathrm{OR}=0.65, \mathrm{CI}=0.34-1.25, p=0.20)$.

In precontemplators, mediation analyses showed two processes of change that partially mediated the relationship between disengagement beliefs and forward stage transition (see Table 5). Adding consciousness raising and self-evaluation to the model resulted in a significant increase in the

\footnotetext{
${ }^{1}$ The $\chi^{2}$-value represents the model chi-square values of the model including disengagement beliefs deducted from the model chi-square values of the model including both disengagement beliefs and the mediator.
} 
Table 5

Prediction of forward stage transition and quitting by disengagement beliefs and the processes of change

\begin{tabular}{|c|c|c|c|c|c|c|}
\hline \multirow[b]{3}{*}{ Variable } & \multicolumn{4}{|c|}{ Forward stage transition } & \multirow{2}{*}{\multicolumn{2}{|c|}{$\frac{\text { Actual quitting }}{\text { All stages }}$}} \\
\hline & \multicolumn{2}{|c|}{ All stages } & \multicolumn{2}{|c|}{ Precontemplators } & & \\
\hline & OR & $95 \% \mathrm{CI}$ & OR & $95 \% \mathrm{CI}$ & OR & $95 \% \mathrm{CI}$ \\
\hline \multicolumn{7}{|l|}{ Step 1} \\
\hline Disengagement beliefs & $0.53 * * *$ & $0.36-0.76$ & $0.47 * *$ & $0.29-0.75$ & $0.62 *$ & $0.40-0.98$ \\
\hline \multicolumn{7}{|l|}{ Step 2} \\
\hline Disengagement beliefs & 0.69 & $0.45-1.04$ & $0.58 *$ & $0.35-0.95$ & 0.79 & $0.47-1.31$ \\
\hline Consciousness raising & $1.61 * * *$ & $1.23-2.12$ & $1.72 * *$ & $1.19-2.49$ & $1.47 *$ & $1.04-2.07$ \\
\hline Disengagement beliefs & $0.63^{*}$ & $0.42-0.96$ & $0.55^{*}$ & $0.33-0.90$ & 0.74 & $0.45-1.23$ \\
\hline Self-evaluation & $1.34^{*}$ & $1.04-1.71$ & $1.44^{*}$ & $1.06-1.97$ & 1.29 & $0.94-1.76$ \\
\hline Disengagement beliefs & $0.53 * * *$ & $0.36-0.78$ & $0.50 * *$ & $0.31-0.80$ & & \\
\hline Dramatic relief & 1.03 & $0.76-1.39$ & 1.28 & $0.88-1.87$ & & \\
\hline Disengagement beliefs & $0.55 * *$ & $0.38-0.81$ & $0.50 * *$ & $0.31-0.81$ & & \\
\hline Reinforcement management & 1.42 & $0.90-2.24$ & 1.90 & $0.95-3.80$ & & \\
\hline Disengagement beliefs & $0.56^{* *}$ & $0.38-0.82$ & & & 0.68 & $0.42-1.09$ \\
\hline Stimulus control & $1.92 * *$ & $1.18-3.15$ & & & $2.02 * *$ & $1.12-3.62$ \\
\hline Disengagement beliefs & $0.57 * *$ & $0.39-0.84$ & & & 0.68 & $0.43-1.09$ \\
\hline Helping relationship & $2.06^{* * *}$ & $1.33-3.19$ & & & $1.74 *$ & $1.02-2.99$ \\
\hline
\end{tabular}

$\mathrm{OR}=$ odds ratio; $\mathrm{CI}=$ confidence interval.

$* p<0.05$.

$* * p<0.01$.

$* * * p<0.001$.

explained variance, with Nagelkerke $R^{2}=0.16\left(\chi^{2}(1, N=284)=8.17, p<0.05\right)$ and Nagelkerke $R^{2}=0.14\left(\chi^{2}(1, N=284)=5.06, p<0.05\right)$, respectively. However, disengagement beliefs remained a significant predictor of forward stage transition (see Table 5). In precontemplators, dramatic relief, reinforcement management, stimulus control, and helping relationship did not have a mediating role in the relation between disengagement beliefs and forward stage transition.

\section{Discussion}

Our findings indicate that having stronger disengagement beliefs seems to be an inhibitor of the motivation to quit smoking. We found that disengagement beliefs are associated with forward stage transition and stronger disengagement beliefs are indicative of less actual quitting over the following 8 months. These results correspond with findings from previous studies showing negative relations between both disengagement beliefs and intention to quit (Dijkstra, 2003; Dijkstra et al., 1999; Dijkstra et al., 2003; Oakes et al., 2004; Olshavsky \& Summers, 1974) and quit attempts (Dijkstra, 2003; Dijkstra et al., 1999; Dijkstra et al., 2003).

In addition, stronger disengagement beliefs in the total sample were associated with less engagement in processes that facilitate quitting smoking, i.e., self-evaluation, consciousness raising, dramatic relief, reinforcement management, stimulus control, and helping relationship. There was, however, no significant association between disengagement beliefs and two processes, namely environmental evaluation and counterconditioning. An explanation for the absence of an association 
between disengagement beliefs and environmental evaluation may be that disengagement beliefs are mostly related to one's own health ("it's not all that bad"). It is therefore possible that disengagement beliefs are not related to the evaluation of the effect of one's smoking on the environment. In case of counterconditioning, it was suggested earlier that increased use of counterconditioning is a direct result of quitting, and that once a smoker quits, he or she is forced to replace smoking with something else (Segan, Borland, \& Greenwood, 2002). Because of the proposed direct relation between counterconditioning and quitting, once a smoker makes use of counterconditioning, he or she is probably already considerably determined to quit and therefore no longer susceptible to disengagement beliefs.

Some evidence was found for a mediating role of the processes of change in the association of disengagement beliefs with forward stage transition and actual quitting. This mediating role was, however, not very substantial. After controlling for almost all processes of change, an assumed distal construct like disengagement beliefs remains directly associated with forward stage transition. Consciousness raising was the only process that fully mediated this relation. Additional analyses suggested that all processes of change together explained about $16 \%$ of the variance in forward stage transition (Nagelkerke $R^{2}$ ), while disengagement beliefs alone account for $7 \%$ of the variance. Previous research by Herzog, Abrams, Emmons, Linnan, and Shadel (1999) on the utility of the processes of change in predicting movement through the stages of change reported that the processes of change were not predictive of progressive movement through the stages of change. In our study, however, we found that specific processes of change were related to forward stage transition. Furthermore, Segan et al. $(2002,2004)$ found no relationship between use of the behavioral processes of change and making and sustaining a quit attempt. In the present study, the relation between disengagement beliefs and actual quitting was mediated by three processes of change. Having disengagement beliefs seems to prevent consciousness raising, stimulus control, and helping relationship processes, and less engagement in these processes in turn prevents actual quitting. It must be noted, however, that we tested the predictive ability of the processes of change across the whole spectrum of the stages of change, whereas the studies by Segan et al. involved only smokers in the preparation phase (Segan et al., 2002), and smokers in the contemplation phase and preparation phase (Segan et al., 2004).

In our study, results for precontemplators only, showed some differences compared to the results for the total sample consisting of precontemplators, contemplators, as well as preparers. First, there was no significant relationship between adhering to disengagement beliefs and actual quitting, and, secondly, consciousness raising was only a partial mediator and there was no partial mediation of stimulus control and helping relationship. These differences might be explained by the lack of intention or motivation to change that is characteristic for smokers in the precontemplation stage. It will be less likely that precontemplators will quit 8 months later than smokers in the contemplation and preparation stage, who have already started to consider behavioral change or have already taken steps in the direction of quitting. The absence of stimulus control and helping relationship as partial mediators might be explained by the more frequent usage of these behavioral processes in the later stages of change. It is less likely that these processes play a role in the precontemplation stage or that they have a mediating function in the relation between disengagement beliefs and forward stage transitions. In addition, our data may have limited statistical power to detect a significant relation between disengagement beliefs and actual quitting or a mediating role of the processes of change in precontemplators.

The findings of the present longitudinal study indicate that smokers tend to adhere to disengagement beliefs, and that strong adherence to disengagement beliefs inhibits them from making 
progression towards cessation and actual quitting. In order to motivate smokers to quit, it seems important to challenge their disengagement beliefs. In the study by Oakes et al. (2004) on selfexempting beliefs, it was reported that it is essential to make the relative risks of smoking more salient to smokers; interventions should aim at improving knowledge by making the facts more credible, or by using genuinely new facts in order to challenge the beliefs and change the balance of worth away from smoking. Challenging the disengagement beliefs of smokers by increasing their awareness is, however, a difficult task. In agreement with the cognitive dissonance theory (Festinger, 1957), there is a chance that the improved knowledge and introduction of new and/or more credible facts will give rise to perceived threat and thereby to an even stronger adherence to disengagement beliefs. It is therefore important to find a way of challenging disengagement beliefs without increasing the perceived threat in such a way that it results in a higher need for disengagement beliefs. A way to achieve this may be to use arguments that directly challenge disengagement beliefs and that undermine them, i.e., debunk the myth. For instance, the argument of knowing smokers aged 80 years that are in good health could be challenged by the counterargument that for every smoker aged 80 years, two aged 60 years have already died.

Taking the results of the present study into account, it seems worthwhile to combine the challenging of disengagement beliefs with an attempt to increase engagement in those processes of change that have shown to be of importance in the progression towards cessation and actual quitting. It has already been suggested that an effective way to convince people to accept recommendations is to combine the offer of threatening information with efficacy messages which offer responses that appear easy to accomplish (Witte \& Allen, 2000). Defensive reactions to threatening information or fear appeals can be prevented by offering behavior recommendations and alternatives (Das, De Wit, \& Stroebe, 2003). Encouraging smokers to engage in consciousness raising, stimulus control, and helping relationship after challenging their disengagement beliefs by providing debiasing information may therefore be an effective method to encourage smoking cessation. Future research addressing this research topic is, however, still needed.

The present study had some limitations. First, the method of recruitment may have led to a selective sample of smokers, related to the motivation to participate. In the recruitment procedure, however, care was taken to minimize a selection bias by mentioning explicitly that participants did not have to quit smoking or remain quitted to join the study. Furthermore, it was stated that their answers were not related to their chances of winning one of the prizes, that all data would be confidential and that respondents had the opportunity to withdraw from the study whenever they wanted to, without any further obligations. A second limitation is that the group of precontemplators was relatively large compared to the group of contemplators and preparers. This could be at the cost of the generalizability of the results to the smoking population at large. However, results from another Dutch study (Stivoro-rookvrij, 2005) showed that among Dutch smokers $70 \%$ was in the precontemplation stage, $18 \%$ in the contemplation stage, and $12 \%$ in the preparation stage; this representative Dutch sample shows a similar distribution to the sample used in the present study, and indicates that in, The Netherlands, the group of precontemplators is relatively large compared to the group of contemplators and preparers.

In conclusion, the present longitudinal study showed a clear relationship between disengagement beliefs and future plans to quit smoking, as well as actual cessation. We explored these relations further by taking into account possible mediators of these relationships, i.e., the processes of change. This study aimed to enhance the understanding of having disengagement beliefs in relation to smoking cessation, and its findings may be useful for the development of interventions to challenge the beliefs that are held by many smokers. 


\section{Acknowledgments}

This study was financed by The Netherlands Organization for Health Research and Development and the Royal Dutch Academy of Arts and Sciences.

\section{References}

Bandura, A. (1986). Social foundations of thought and action. A social cognitive theory. Englewood Cliffs, NJ: Prentice-Hall.

Bandura, A., Barbaranelli, C., Caprara, G. V., \& Pastorelli, C. (1996). Mechanisms of moral disengagement in the exercise of moral agency. Journal of Personality and Social Psychology, 71, 364-374.

Baron, R. M., \& Kenny, D. A. (1986). The moderator-mediator variable distinction in social psychological research: Conceptual, strategic, and statistical considerations. Journal of Personality and Social Psychology, 51, 1173-1182.

Chapman, S., Wong, W. L., \& Smith, W. (1993). Self-exempting beliefs about smoking and health: Differences between smokers and ex-smokers. American Journal of Public Health, 83(2), 215-219.

Connors, G. J., Donovan, D. M., \& DiClemente, C. C. (2001). Substance abuse treatment and the stages of change: Selecting and planning interventions. New York: Guilford Press.

Das, E. H. H. J., De Wit, J. B. F., \& Stroebe, W. (2003). Fear appeals motivate acceptance of action recommendations: Evidence for a positive bias in the processing of persuasive messages. Personality and Social Psychology Bulletin, 29, 650-664.

Dijkstra, A. (2003). Self-evaluative emotions and motivation to quit smoking. Gedrag \& Gezondheid, 31, 30-40.

Dijkstra, A., Bakker, M., \& De Vries, H. (1997). Subtypes within a sample of precontemplating smokers: A preliminary extension of the stages of change. Addictive Behaviors, 22(3), 327-337.

Dijkstra, A., \& Brosschot, J. (2003). Worry about health in smoking behaviour change. Behaviour Research and Therapy, 41, $1081-1092$.

Dijkstra, A., De Vries, H., Kok, G., \& Roijackers, J. (1999). Self-evaluation and motivation to change: Social cognitive constructs in smoking cessation. Psychology and Health, 14, 747-759.

Dijkstra, A., Roijackers, J., \& De Vries, H. (1998). Smokers in four stages of readiness to change. Addictive Behaviors, 23(3), $339-350$.

Dijkstra, A., Tromp, D., \& Conijn, B. (2003). Stage-specific psychological determinants of stage transition. British Journal of Health Psychology, 8, 423-437.

Festinger, L. (1957). A theory of cognitive dissonance. Oxford, England: Row, Peterson.

Herzog, T. A., Abrams, D. B., Emmons, K. M., Linnan, L. A., \& Shadel, W. G. (1999). Do processes of change predict smoking stage movements? A prospective analysis of the transtheoretical model. Health Psychology, 18, 369-375.

Johnson, R. E. (1968). Smoking and the reduction of cognitive dissonance. Journal of Personality and Social Psychology, 9 , $260-265$.

Kristeller, J. L., Rossi, J. S., Ockene, J. K., Goldberg, R., \& Prochaska, J. O. (1992). Processes of change in smoking cessation: A cross-validation study in cardiac patients. Journal of Substance Abuse, 4, 263-276.

McMaster, C., \& Lee, C. (1991). Cognitive dissonance in tobacco smokers. Addictive Behaviors, 16(5), 349-353.

Oakes, W., Chapman, S., Borland, R., Balmford, J., \& Trotter, L. (2004). Bulletproof sceptics in life's jungle”: Which selfexempting beliefs about smoking most predict lack of progression towards quitting? Preventive Medicine, 39, 776-782.

O'Connor, E. A., Carbonari, J. P., \& DiClemente, C. C. (1996). Gender and smoking cessation: A factor structure comparison of processes of change. Journal of Consulting and Clinical Psychology, 64, 130-138.

Olshavsky, R. W., \& Summers, J. O. (1974). A study of the role of beliefs and intentions in consistency restoration. Journal of Consumer Research, 1, 63-70.

Prochaska, J. O., DiClemente, C. C., \& Norcross, J. C. (1992). In search of how people change: Applications to addictive behaviors. American Psychologist, 47(9), 1102-1114.

Prochaska, J. O., Norcross, J. C., Fowler, J. L., Follick, M. J., \& Abrams, D. B. (1992). Attendance and outcome in a work site weight control program: Processes and stages of change as process and predictor variables. Addictive Behaviors, 17(1), $35-45$.

Prochaska, J. O., Velicer, W. F., DiClemente, C. C., \& Fava, J. (1988). Measuring processes of change: Applications to the cessation of smoking. Journal of Consulting and Clinical Psychology, 56(4), 520-528. 
Rosen, C. S. (2000). Is the sequencing of change processes by stage consistent across health problems? A meta-analysis. Health Psychology, 19(6), 593-604.

Segan, C. J., Borland, R., \& Greenwood, K. M. (2002). Do transtheoretical model measures predict the transition from preparation to action in smoking cessation? Psychology and Health, 17, 417-435.

Segan, C. J., Borland, R., \& Greenwood, K. M. (2004). What is the right thing at the right time? Interactions between stages and processes of change among smokers who make a quit attempt. Health Psychology, 23, 86-93.

Stephens, S., Cellucci, T., \& Gregory, J. (2004). Comparing stage of change measures in adolescent smokers. Addictive Behaviors, 29(4), 759-764.

Stivoro-rookvrij (2005). Roken, de harde feiten: Volwassenen 2004 [Smoking, the facts: Adults 2004]. The Hague, The Netherlands: Stivoro-rookvrij.

Velicer, W. F., Prochaska, J. O., Rossi, J. S., \& Snow, M. G. (1992). Assessing outcome in smoking cessation studies. Psychological Bulletin, 111, 23-41.

Voeten, M. J. M., \& Van den Bercken, J. H. L. (2003). Lineaire regressieanalyse [Linear regression analysis]. Groningen, The Netherlands: Stenfert Kroese.

Wicklund, R. A., \& Brehm, J. W. (1976). Perspectives on cognitive dissonance. Hillsdale N.J.: Erlbaum New York.

Witte, K., \& Allen, M. (2000). A meta-analysis of fear appeals: Implications for effective public health campaigns. Health Education and Behavior, 27, 591-615. 